\title{
Freeze dried multicomponent inclusion complexes of quercetin: Physicochemical evaluation and pharmacodynamic study
}

\author{
Anita KULKARNI ${ }^{1}$ (D), Remeth DIAS $2 *$ (D) , Vishwajeet GHORPADE ${ }^{3}$ (D) \\ 1 Department of Pharmaceutical Chemistry, Government College of Pharmacy, Karad, Maharashtra, India \\ 2 Department of Pharmacy, Government Polytechnic, Jalgaon, Maharashtra, India. \\ 3 Department of Pharmaceutics, YSPM's Yashoda Technical Campus, Wadhephata, Satara-415011, Maharashtra, \\ India. \\ * Corresponding Author. E-mail: rjdias75@rediffmail.com (R.D.).
}

Received: 21 September 2018 / Revised: 19 November 2018/ Accepted: 19 November 2018

\begin{abstract}
The present study was undertaken to investigate the effect of cyclodextrin $(\mathrm{CD})$ complexation in presence of hydrophilic polymer on physicochemical properties as well as anti- inflammatory activity of quercetin (QUN). The initial phase solubility studies were carried out in presence and absence of hydrophilic polymers (hydroxypropylmethylcellulose, polyvinylpyrrolidone K30 and poloxamer 188) to study their effect on the stability and complexation efficiency of CDs. The binary (QUN- $\beta C D$ and QUN-HP $\beta C D)$ and multicomponent (QUN- $\beta C D-P O L O$ and QUN-HP $\beta C D-P O L O)$ inclusion complexes of QUN prepared using lyophilization technique. The complexes were subjected to DSC, ATR-FTIR, XRPD and SEM analysis, and evaluated for drug content and saturation solubility. The phase solubility studies revealed the formation of QUN- $\beta C D$ and QUN-HP $\beta C D$ complexes with 1:1 stoichiometry. The incorporation of POLO increased the stability as well as complexation efficiency of CDs. FTIR and DSC analysis indicated hydrogen bonding interaction POLO with QUN and CDs. XRD and SEM analysis revealed greater amorphization in case of multicomponent inclusion complexes. All complexes showed uniform drug content. QUNHPßCD-POLO exhibited maximum solubility than the physical mixtures and other complexes. The pure QUN and QUN-HP $\beta C D-P O L O$ were tested for in vivo anti-inflammatory activity by Carrageenan induced rat paw edema method. QUN-HP $\beta C D-P O L O$ exhibited significant increase in anti-inflammatory activity as compared to pure QUN.
\end{abstract}

KEYWORDS: Quercetin; $\beta$-cyclodextrin; hydroxypropyl- $\beta$-cyclodextrin; lyophilization; ternary complex.

\section{INTRODUCTION}

Quercetin (QUN) is a bioflavonoid (3,5,7,3', $4^{\prime}$-pentahydroxyflavone) widely distributed in many plants (see Figure 1). It is also a frequent component of major dietary constituents such as onions, apples, red wine and green tea. Flavonoids, intensely coloured polyphenolic phytochemicals, exhibit various biological activities. Nowadays research is being focused on the antioxidant, antitumour, antiinflammatory and antibacterial activity of flavonoids. In literature wide range of biological properties of QUN are reported which are often related to its antioxidant activity. Besides, it is also known for its anti-inflammatory, antihypertensive, vasodilator effects, antiobesity, antihypercholesterolemic and antiatherosclerotic activities [1-4]. QUN shows a strong inhibitory effect on the growth of several human and animal cancer cell lines and enhances the antiproliferative effect of cisplatin both in vitro and in vivo. However, the oral bioavailability of QUN is found to be less than $17 \%$ in rats and approximately $1 \%$ in humans which may be due to its low aqueous solubility [5-7].

From past few years, technique of cyclodextrin inclusion complexation is being widely used to improve the physicochemical properties of drugs such as solubility, chemical stability and bioavailability [5,8]. Cyclodextrins (CDs) are cyclic oligosaccharides consisting (a-1, 4)-linked a-D-glucopyranose units containing a relatively hydrophobic central cavity and hydrophilic outer surface [9]. In an aqueous environment, cyclodextrins form inclusion complexes with many lipophilic drug molecules through a process in which water molecules located inside the central cavity are replaced by either the whole drug molecule or more

How to cite this article: Kulkarni A, Dias R, Ghorpade V. Freeze dried multicomponent inclusion complexes of quercetin: Physicochemical evaluation and pharmacodynamic study. J Res Pharm. 2019; 23(3): 403-414. 
frequently, by some lipophilic structure of the molecule. The natural cyclodextrins, in particular $\beta$ cyclodextrin $(\beta C D)$, have limited aqueous solubility and their complex formation with<smiles>O=c1c(O)c(-c2ccc(O)c(O)c2)oc2cc(O)cc(O)c12</smiles>

Figure 1. Chemical structure of QUN.

lipophilic compounds frequently results in precipitation of solid cyclodextrin complexes [10]. The application of $\beta C D$ in the pharmaceutical formulations is limited owing to its low aqueous solubility [5].

2-hydroxypropyl- $\beta$-cyclodextrin (HP $\beta C D$ ); a hydroxyalkyl $\beta$-bcyclodextrin derivative has been successfully employed in pharmaceutical formulations due to its amorphous nature and enhanced water solubility than $\beta C D$ [11]. However, the amount of HP $\beta C D$ to be used in the pharmaceutical formulations is limited due to its toxicity [12]. The problems associated with $\beta C D$ and HP $\beta C D$ can be overcome by addition of small amounts of auxiliary substances such as hydrophilic polymers [13], hydroxyl acids [14] and/or amino acids [8] to the complexation media. This results in the formation of multicomponent inclusion complexes of CDs, where the auxiliary substances improve the complexation efficiency of CDs [11].

There are some reports where inclusion complexes of QUN with $\beta C D$ and HP $\beta C D$ have been prepared to enhance its solubility using freeze drying [5] and spray drying techniques [1]. Besides, the effect of complexation of QUN with three kinds of CDs in solution state on the antioxidant activity of QUN has been studied by Jullian and coworkers [3]. The complexes of QUN with $\beta C D, H P \beta C D$ and sulfobutyl- $\beta C D$ in solution state were studied in order to investigate the effect of complexation on chemical stability and water solubility of QUN [2]. To our knowledge, no reports related to the effect of multicomponent inclusion complexes of QUN with CDs and hydrophilic polymers on its solubility and anti-inflammatory activity are available.

The aim of this study was to prepare freeze dried multicomponent (ternary) inclusion complexes of QUN with $\beta C D$ and HP $\beta C D$ in presence of a suitable hydrophilic polymer in order to minimize the amount of CDs, increase the stability of the formed inclusion complexes and enhance the solubility of QUN so as to maximize its anti-inflammatory activity. Phase solubility studies were performed to study the stoichiometry between QUN and CDs, and to select the hydrophilic polymer that increases the stability of the formed complexes and improves the complexation efficiency of CDs. The prepared complexes were characterized by attenuated total reflectance-fourier transform infrared spectroscopy (ATR-FTIR), differential scanning calorimetry (DSC), scanning electron microscopy (SEM) and X-ray powder diffractometry (XRPD). The complexes were evaluated for saturation solubility and drug content. The in vivo anti-inflammatory activity of the complex exhibiting high solubility was evaluated using Carrageenan induced rat paw edema method.

\section{RESULTS AND DISCUSSION}

\subsection{Phase solubility studies and interaction of QUN with CDs}

The phase solubility diagram of QUN in aqueous solutions of $\beta C D$ and HP $\beta C D$ in the presence or absence of hydrophilic polymers (HPMC, PVP and POLO) are shown in Figure 2 (a and b). These diagrams exhibited a linear relationship between the amount of solubilized QUN and concentration of solution of CDs (A $A_{L}$-type of curves) which signifies formation of water soluble complexes [15]. Table 1 shows the values of slope, stability constant $(\mathrm{Kc})$ and complexation efficiency of the systems considered under phase solubility studies. The slope of phase solubility curves for all the systems was found to be less than one indicating 1:1 stoichiometry between QUN and CDs [16]. The presence of hydrophilic polymer caused increase in the stability of the formed complexes along with enhancement in the complexation efficiency of the CDs. This can be attributed to the molecular interactions in between QUN, CDs and hydrophilic polymers such as hydrogen bonding, formation of hydrophobic bonds and van der Waals interaction [17-19]. 


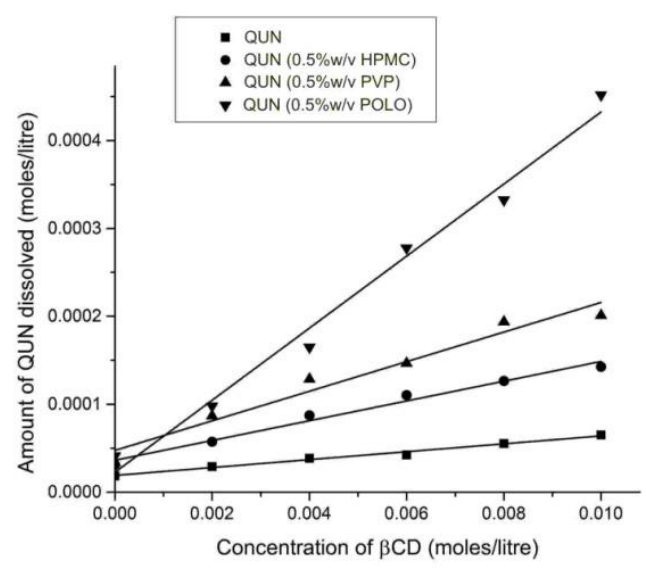

A

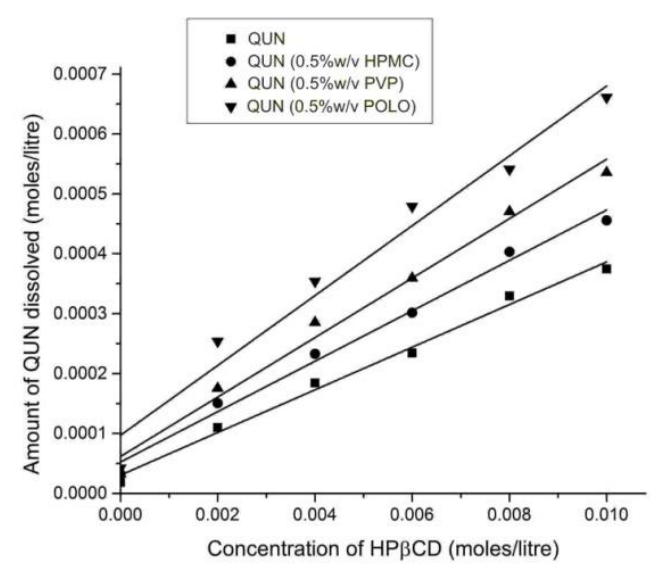

B

Figure 2. Phase solubility profile of QUN- $\beta C D(A)$ and QUN-HP $\beta C D(B)$ systems in distilled water $(\boldsymbol{\bullet})$ and in presence of $0.5 \% \mathrm{w} / \mathrm{v} \operatorname{HPMC}(\bullet), 0.5 \% \mathrm{w} / \mathrm{v} \operatorname{PVP}(\boldsymbol{\Delta})$ and $0.5 \% \mathrm{w} / \mathrm{v} \operatorname{POLO}(\boldsymbol{\nabla})$.

Table 1. Phase solubility data of binary and ternary inclusion complexes of QUN with $\beta C D$ and HP $\beta C D$.

\begin{tabular}{|c|c|c|c|c|}
\hline \multirow[t]{2}{*}{ QUN/CD systems } & \multicolumn{4}{|c|}{ Phase solubility parameters } \\
\hline & Slope & $\mathrm{K}_{\mathrm{c}, 1: 1}\left(\mathrm{M}^{-1}\right)$ & C.E. & $\overline{S_{o} \text { (moles/litre) }}$ \\
\hline QUN/ $\beta C D$ & 0.0044 & $240.29 \pm 6.86$ & 0.0045 & $1.86 \times 10^{-5}$ \\
\hline $\begin{array}{l}\text { QUN/ } \beta C D / H P M C \\
(0.5 \% w / w)\end{array}$ & 0.0112 & $597.07 \pm 11.98$ & 0.0113 & $3.12 \times 10^{-5^{*}}$ \\
\hline $\begin{array}{l}\text { QUN/ } \beta C D / P V P \\
(0.5 \% w / w)\end{array}$ & 0.0168 & $888.86 \pm 8.32$ & 0.0171 & $3.32 \times 10^{-5^{*}}$ \\
\hline $\begin{array}{l}\text { QUN/ } \beta C D / P O L O \\
(0.5 \% \mathrm{w} / \mathrm{w})\end{array}$ & 0.0409 & $2111.71 \pm 14.42$ & 0.0427 & $4.13 \times 10^{-5^{*}}$ \\
\hline QUN/HP $\beta C D$ & 0.0355 & $1842.43 \pm 13.16$ & 0.0368 & $1.86 \times 10^{-5}$ \\
\hline $\begin{array}{l}\text { QUN/HP } \beta C D / H P M C \\
(0.5 \% \mathrm{w} / \mathrm{w})\end{array}$ & 0.0445 & $2286.90 \pm 10.16$ & 0.0466 & $3.12 \times 10^{-5^{*}}$ \\
\hline $\begin{array}{l}\text { QUN/HP } \beta C D / P V P \\
(0.5 \% w / w)\end{array}$ & 0.0495 & $2531.76 \pm 7.42$ & 0.0521 & $3.32 \times 10^{-5^{*}}$ \\
\hline $\begin{array}{l}\text { QUN/HP } \beta C D / P O L O \\
(0.5 \% \mathrm{w} / \mathrm{w})\end{array}$ & 0.0634 & $3193.08 \pm 16.81$ & 0.0677 & $4.13 \times 10^{-5^{*}}$ \\
\hline
\end{tabular}

$\mathrm{K}_{\mathrm{c}, 1: 1}$ : stability constant; $\mathrm{S}_{\mathrm{o}}$ : intrinsic solubility; QUN: quercetin; $\beta \mathrm{CD}$ : $\beta$-cyclodextrin; HP $\beta C D$ : hydroxypropyl- $\beta$-cyclodextrin; HPMC: hydroxypropyl-methylcellulose; PVP: polyvinylpyrrolidone K30; POLO: poloxamer 188. The values of slope C.E. and So are expressed as mean $(n=3)$ whereas value of $K_{c, 1: 1}$ is expressed as mean \pm S.D. $(n=3)$. * indicates solubility of QUN in presence of respective hydrophilic polymers.

Table 2 represents the Gibbs free energy change $\left(\mathrm{G}_{\mathrm{tr}}{ }^{\circ}\right)$ in the systems with increase in the concentration of CDs. A decrease in the $G_{t r^{\circ}}$ values with respect to increase in the $C D$ concentration indicated the spontaneous nature of QUN solubilization suggesting that the reaction became more favorable with the increase in the concentration of $\mathrm{CDs}$. The negative $\mathrm{G}_{\mathrm{tr}}{ }^{\circ}$ values indicated the exothermic nature of the complexation process [20]. The system comprised of QUN, HP $\beta C D$ and POLO showed maximum stability, high complexation efficiency and lowest value of $\mathrm{G}_{\mathrm{tr}^{\circ}}$. This may be due to high solubility of HP $\beta C D$ than $\beta C D$ and ability of POLO to enhance the solubilizing efficiency of $\mathrm{HP} \beta C D$ by interacting with the functional groups present on the exterior of the HP $\beta C D$ and QUN [21]. Due to its amphiphilic nature, POLO can also improve the solubility of the free uncomplexed drug [22]. As POLO was found to be more efficient ternary component amongst the selected polymers, it was used for the preparation of the freeze dried multicomponent inclusion complexes of QUN. 
Table 2. Gibbs free energy change ( $\left.\Delta \mathrm{G} \_t r\right)$ in Joules/ mole.

\begin{tabular}{|c|c|c|c|c|c|}
\hline \multirow[t]{2}{*}{ System } & \multirow[t]{2}{*}{ Moles of CDs } & \multicolumn{4}{|c|}{ QUN/ $\beta C D$ system } \\
\hline & & $\begin{array}{l}\text { Without } \\
\text { polvmer }\end{array}$ & $\begin{array}{l}\text { HPMC } \\
(0.5 \% \mathrm{w} / \mathrm{v})\end{array}$ & PVP (0.5\%w/v) & $\begin{array}{l}\text { POLO } \\
(0.5 \% \mathrm{w} / \mathrm{v})\end{array}$ \\
\hline \multirow[t]{5}{*}{ QUN $/ \beta C D$} & 0.002 & -1106.59 & -2763.41 & -3775.98 & -4066.73 \\
\hline & 0.004 & -1787.38 & -3788.49 & -4734.52 & -5344.12 \\
\hline & 0.006 & -2019.85 & -4359.08 & -5057.65 & -6619.67 \\
\hline & 0.008 & -2671.12 & -4692.82 & -5739.18 & -7060.87 \\
\hline & 0.01 & -3065.31 & -4988.21 & -5829.53 & -7812.84 \\
\hline \multirow[t]{5}{*}{ QUN/HP $\beta C D$} & 0.002 & -4351.07 & -4784.12 & -5493.93 & -5882.08 \\
\hline & 0.004 & -5618.43 & -6189.87 & -6686.10 & -7215.45 \\
\hline & 0.006 & -6204.44 & -6823.86 & -7253.22 & -7956.97 \\
\hline & 0.008 & -7040.59 & -7535.44 & -7911.77 & -8254.63 \\
\hline & 0.01 & -7353.55 & -7949.54 & -8228.41 & -8896.33 \\
\hline
\end{tabular}

CDs: cyclodextrins; QUN: quercetin; $\beta C D$ : $\beta$-cyclodextrin; $\mathrm{HP} \beta C D$ : hydroxypropyl- $\beta$-cyclodextrin; HPMC: hydroxypropylmethylcellulose; PVP: polyvinylpyrrolidone K30; POLO: poloxamer 188.

\subsection{Characterization of the inclusion complexes}

\subsubsection{DSC analysis}

DSC can be used to investigate the interaction between host and guest molecules. When guest molecules are included in CD cavity, their melting points usually shift to a different temperature or disappear [17]. DSC patterns of QUN and all complexes are shown in Figure 3. The thermogram of QUN showed a characteristic endothermic peak at $319.10^{\circ} \mathrm{C}$ close to its melting point 316.0 indicating presence of crystalline phase. The broad endothermic peak at $126.59^{\circ} \mathrm{C}\left(\mathrm{T}_{\text {onset }}=99.94^{\circ} \mathrm{C}\right)$ represents removal of water of crystallization as QUN is a dihydrate molecule [23]. The DSC thermogram of $\beta C D$ displayed a broad endotherm at $99.95^{\circ} \mathrm{C}$, indicating a loss of water due to dehydration process. A melting endotherm was observed at $335.32^{\circ} \mathrm{C}$. The thermal curve of pure $\mathrm{HP} \beta \mathrm{CD}$ is characterized by a broad endothermic peak at $75.48{ }^{\circ} \mathrm{C}$, indicating a loss of water due to dehydration process [24].

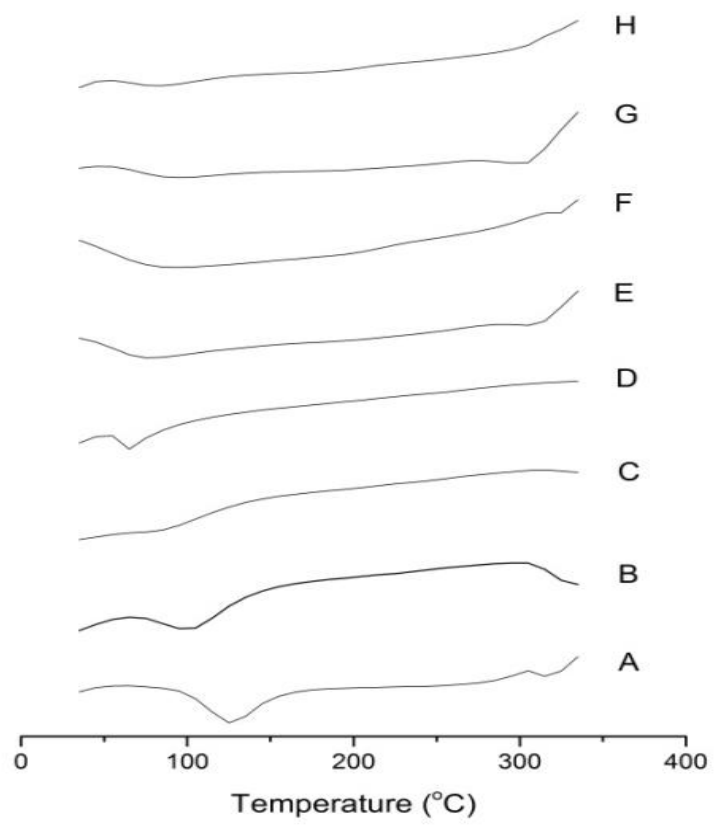

Figure 3. DSC thermograms of QUN (A), $\beta C D(B), H P \beta C D(C), P O L O(D), Q U N-\beta C D(E)$ and QUN-HP $\beta C D$ $(\mathrm{F})$ binary complexes, QUN- $\beta C D-P O L O(G)$ and QUN-HP $\beta C D-P O L O(H)$ ternary complexes. 
It showed melting endotherm at $366.62^{\circ} \mathrm{C}$ corresponding to its melting point. The DSC thermogram of POLO showed a sharp endothermic peak at $60.28^{\circ} \mathrm{C}$ indicating its crystalline nature. In the thermogram of QUN- $\beta C D$ binary complex, the melting endotherm of QUN was found to be diffused at $307.19^{\circ} \mathrm{C}$, while the thermogram of QUN-HP $\beta C D$ binary complex showed a small diffused endothermic peak at $322.78^{\circ} \mathrm{C}$. In case of QUN- $\beta C D-$ POLO ternary complex, the characteristic endothermic peak of QUN was diffused and shifted to $299.52^{\circ} \mathrm{C}$ indicating formation of inclusion complex [25]. The thermogram of QUN-HP $\beta C D-P O L O$ ternary complex showed absence of the endothermic peak indicating strong physical interaction between drug and HP $\beta C D$ in presence of POLO [26].

\subsubsection{ATR-FTIR analysis}

The probable interaction between QUN and CDs in presence and absence of POLO was studied by ATRFTIR. The IR spectra recorded for QUN, $\beta C D, H P \beta C D, P O L O$ and all complexes are shown in Figure 4.

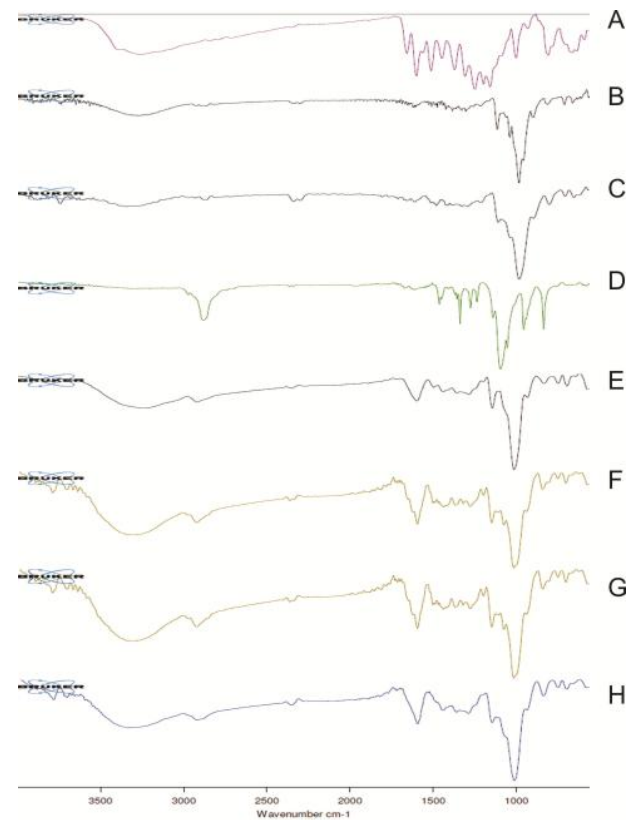

Figure 4. ATR-FTIR spectra of QUN (A), $\beta C D(B), H P \beta C D(C)$, POLO (D), QUN- $\beta C D(E)$ and QUN-HP $\beta C D$ $(\mathrm{F})$ binary complexes, QUN- $\beta$ CD-POLO $(\mathrm{G})$ and QUN-HP $\beta C D-P O L O(\mathrm{H})$ ternary complexes.

The principle absorption peaks of QUN were observed at $3390.44 \mathrm{~cm}^{-1}(\mathrm{O}-\mathrm{H}$ stretching vibration of phenol), $3259.7 \mathrm{~cm}^{-1}, 1660.66 \mathrm{~cm}^{-1}$ ( $\mathrm{C}=\mathrm{O}$ aryl ketonic stretch /aromatic ketonic carbonyl stretching), 2841.66 $\mathrm{cm}^{-1}$ (C-H stretching), $1603.14 \mathrm{~cm}^{-1}$ (C-C aromatic ring stretch), $1374.533 \mathrm{~cm}^{-1}$ (O-H bending of phenols), $1252.33 \mathrm{~cm}^{-1}$ (C-O stretch of aryl ether), $1161.75 \mathrm{~cm}^{-1}$ (C-CO-C stretch and bending in ketone) and $812.39 \mathrm{~cm}^{-1}$ (C-H bending of aromatic hydrocarbon) [27]. The peaks of $\beta C D$ were recorded at $3276.49 \mathrm{~cm}^{-1}(\mathrm{O}-\mathrm{H}$ stretch), $1152.61 \mathrm{~cm}^{-1}, 1078.03 \mathrm{~cm}^{-1}, 1023.99 \mathrm{~cm}^{-1}$ (C- O- C stretch), $997.86 \mathrm{~cm}^{-1}$ and $937.10 \mathrm{~cm}^{-1}$ whereas absorption peaks of HP $\beta C D$ were observed at $3737.23 \mathrm{~cm}^{-1}, 3348.45 \mathrm{~cm}^{-1}$ (O-H stretch), $2929.2 \mathrm{~cm}^{-1}$ (C- H stretch), 1026.41 $\mathrm{cm}^{-1}$ (C-O-C stretch). IR spectrum of POLO shows distinct peaks at $2878.80 \mathrm{~cm}^{-1}$ (C-H stretching aliphatic), $1446.23 \mathrm{~cm}^{-1}, 1341.71 \mathrm{~cm}^{-1}$ (in plane O-H bending), 1279.23, 1241.06 and $1100.17 \mathrm{~cm}^{-1}$ (C-O stretch).

Alterations in the characteristic bands of QUN and CDs were noted in case of binary and ternary complexes. The peaks in formulations were observed to be either shifted to different wavelengths or smoothened or appeared with decreased intensity. The absence of new peaks indicated non covalent interaction in inclusion complexes. In case of QUN- $\beta C D$ complex, the peaks of QUN at $3259.70 \mathrm{~cm}^{-1}, 2841.66$ $\mathrm{cm}^{-1}$ and $1603.14 \mathrm{~cm}^{-1}$, were shifted to $3240.24 \mathrm{~cm}^{-1}, 2918.64 \mathrm{~cm}^{-1}$ and $1599.90 \mathrm{~cm}^{-1}$ respectively while other peaks had also shifted and appeared with reduced intensity or disappeared. Broad peak of $\beta C D$ at $3276.49 \mathrm{~cm}^{-1}$ disappeared, while peak at $1023.99 \mathrm{~cm}^{-1}$ was shifted to $1018.07 \mathrm{~cm}^{-1}$.

In spectrum of QUN-HP $\beta C D$ complex, the principle peaks of QUN at $3259.7 \mathrm{~cm}^{-1}$ and $2841.66 \mathrm{~cm}^{-1}$ shifted to $3299.47 \mathrm{~cm}^{-1}$ and $2922.95 \mathrm{~cm}^{-1}$ while other peaks were either shifted or appeared with decreased intensity. The prominent peak of HP $\beta C D$ at $1026.41 \mathrm{~cm}^{-1}$ was shifted to $1004.11 \mathrm{~cm}^{-1}$. The disappearance of major peaks of QUN in the spectra of binary complexes clearly indicates the formation of inclusion complex. 
The spectrum of QUN- $\beta C D-P O L O$ ternary complex showed shifting of QUN peaks from $3259.7 \mathrm{~cm}^{-1}$ and $2841.66 \mathrm{~cm}^{-1}$ to $3254.72 \mathrm{~cm}^{-1}$ and $2921.34 \mathrm{~cm}^{-1}$ while peak of $\beta C D$ at $1023.99 \mathrm{~cm}^{-1}$ was shifted to 1019.16 $\mathrm{cm}^{-1}$. For QUN-HP $\beta C D-P O L O$ ternary complex, the prominent peaks at $3310.76 \mathrm{~cm}^{-1}, 2918.55 \mathrm{~cm}^{-1}, 1596.69 \mathrm{~cm}^{-}$ 1 and $1015.89 \mathrm{~cm}^{-1}$ were observed All other peaks had either shifted, disappeared or appeared with less intensity. All these changes confirm the strong physical interaction between QUN and both $\beta C D$ and HP $\beta C D$ in the presence of POLO.

\subsubsection{XRPD analysis}

The XRPD patterns of QUN and all complexes are presented in Figure 5. The diffractogram of QUN exhibited prominent peaks at 12.5, 27.3 and $27.4(2 \theta)$ with peak intensities 784, 969 and 1135 respectively indicating crystalline nature of drug. The peak intensities for $\beta C D$ at 12.7, 18.9, 20.9 and $27.2(2 \theta)$ recorded were 1751, 2025, 1577, and 1459 respectively. A typical halo-pattern was recorded for HP $\beta C D$, which showed

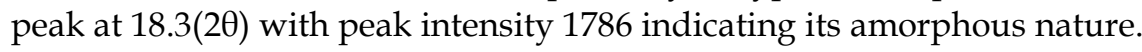

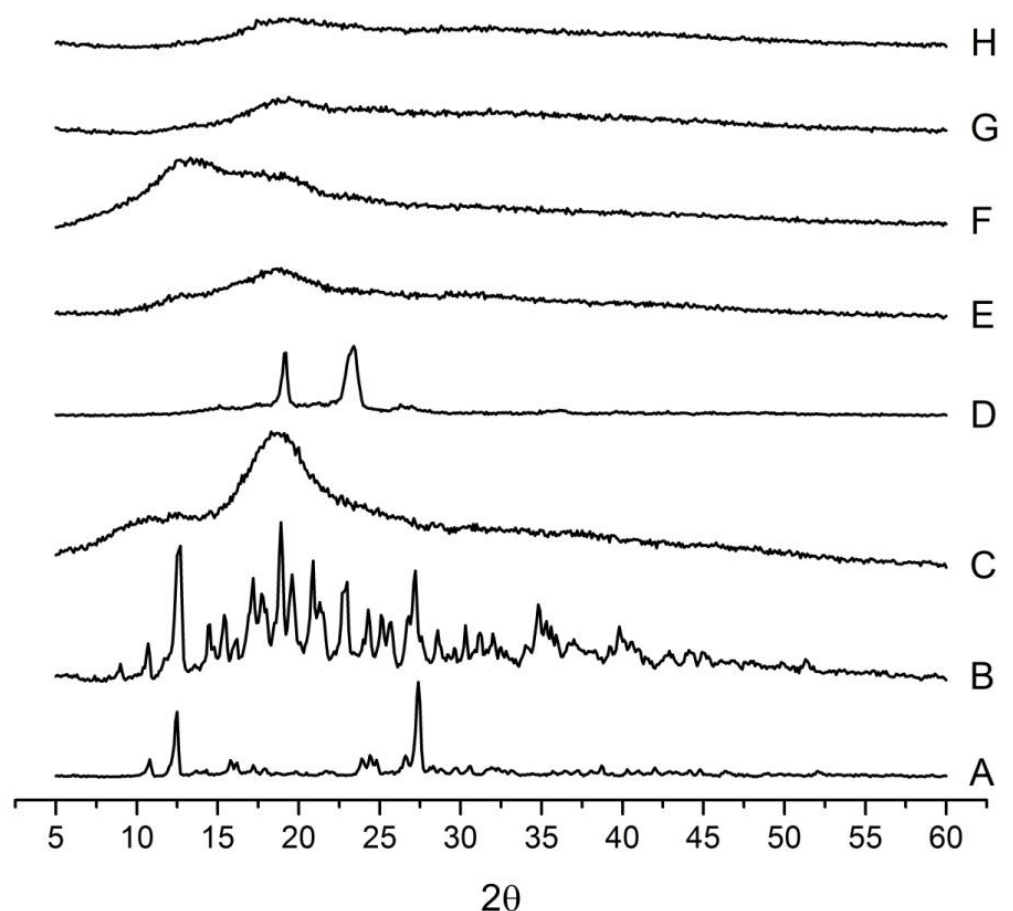

Figure 5. XRPD pattern of QUN (A), $\beta C D(B), H P \beta C D(C), P O L O(D), Q U N-\beta C D(E)$ and QUN-HP $\beta C D(F)$ binary complexes, QUN- $\beta C D-P O L O(G)$ and QUN-HP $\beta C D-P O L O(H)$ ternary complexes.

All the prepared inclusion complexes of QUN exhibited characteristic halo pattern and significant reduction in peak intensities, as compared to pure QUN, confirming reduction in the crystallinity of QUN. The intensity of characteristic peak of QUN at $27.4(2 \theta)$ was reduced to 382 and 323 in case of QUN- $\beta C D$ and QUN-HP $\beta C D$ respectively. For QUN- $\beta C D-P O L O$ and QUN-HP $\beta C D-P O L O$ ternary complexes, the intensity of the same peak was reduced to 313 and 272 respectively. This indicates that QUN-HP $\beta C D-P O L O$ ternary complex exhibited greater amorphization of QUN. The presence of fine peaks in the spectra of complexes may be due to presence of free uncomplexed QUN to some extent in the complex samples.

\subsubsection{SEM analysis}

SEM was used to study the surface morphology of pure drug and complexes (Figure 6). The micrographs of pure drug exhibited presence of long cylindrical/needle shaped crystals. The images of freeze dried inclusion complexes showed a significant change in the morphology of the particles. Both change in shape (needle to flaky) and reduction in particle size were observed which indicates an interaction in between QUN and CDs in presence or absence of POLO, resulting into amorphization of QUN. According to the previous reports, a change in the shape of the crystals and aspects of drug indicates its complexation with CD $[28,29]$. 


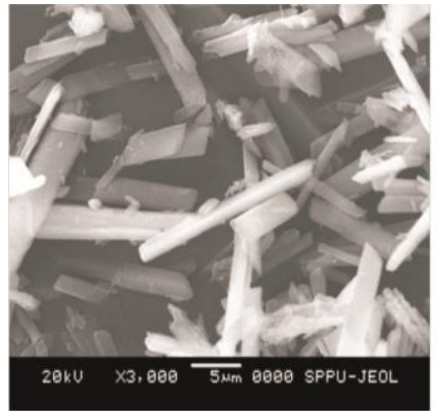

A

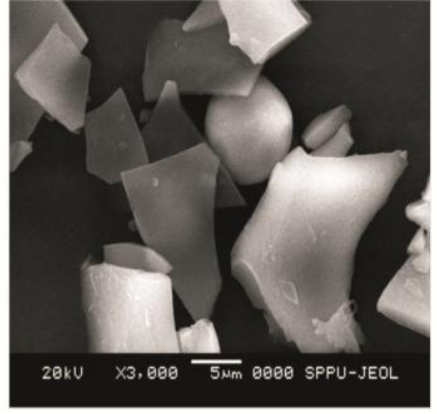

B

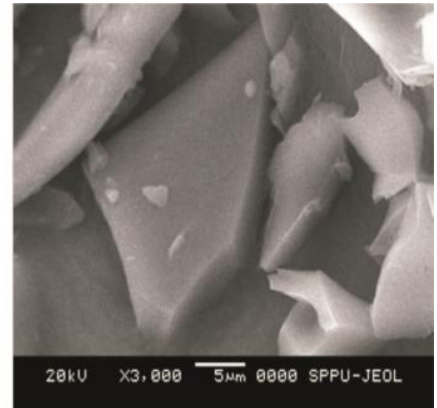

C

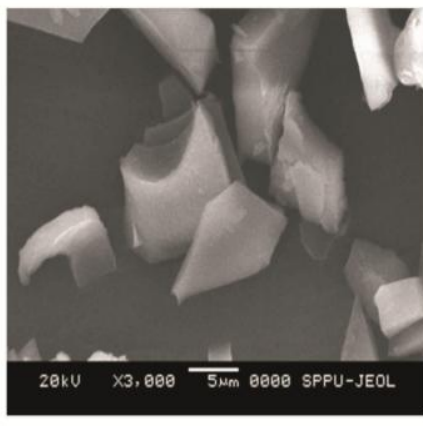

D

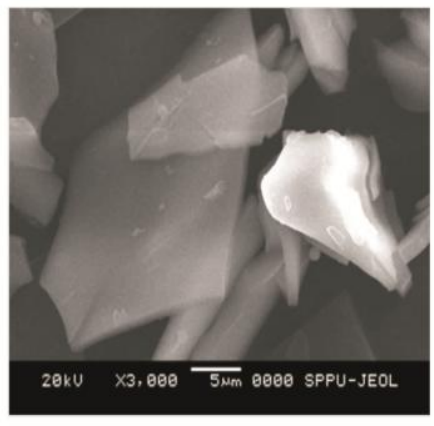

$\mathrm{E}$

Figure 6. SEM photomicrographs of QUN (A), QUN- $\beta C D(B)$ and QUN-HP $\beta C D(C)$ binary complexes,

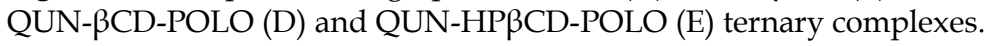

\subsection{Percentage drug content and saturation solubility studies}

Table 3 presents the drug content (\%) and saturation solubility of the physical mixtures and the prepared complexes. The drug content was found to be uniform in all the physical mixtures and complexes ranging within 95.37 to $98.86 \%$.

Table 3. Percentage drug content and saturation solubility of the physical mixtures and complexes

\begin{tabular}{|c|c|c|}
\hline QUN/CD complexes & Drug content $(\%)^{*}$ & $\begin{array}{l}\text { Solubility in water at } 25^{\circ} \mathrm{C} \\
\mathrm{mg} / \mathrm{mL}^{*}\end{array}$ \\
\hline Pure QUN & - & $0.0047 \pm 0.0003$ \\
\hline QUN/ $\beta C D(P M)$ & $98.73 \pm 1.01$ & $0.0071 \pm 0.0002$ \\
\hline QUN/ $\beta C D(F D C)$ & $95.37 \pm 1.51$ & $0.0159 \pm 0.0002$ \\
\hline 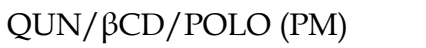 & $97.32 \pm 0.85$ & $0.0098 \pm 0.0007$ \\
\hline 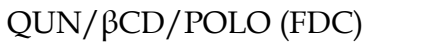 & $96.38 \pm 0.79$ & $0.0505 \pm 0.0142^{\mathrm{ab}}$ \\
\hline QUN/HP $\beta C D(P M)$ & $98.04 \pm 1.08$ & $0.0140 \pm 0.0060$ \\
\hline QUN/HP $\beta C D$ (FDC) & $98.86 \pm 1.49$ & $0.0451 \pm 0.0019 \mathrm{abc}$ \\
\hline QUN/HP $\beta C D / P O L O(P M)$ & $97.11 \pm 1.22$ & $0.0183 \pm 0.0024$ \\
\hline 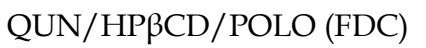 & $96.81 \pm 0.71$ & $0.1602 \pm 0.0053^{\mathrm{abcd}}$ \\
\hline
\end{tabular}

* indicates mean of 3 readings + standard deviation

a indicates significantly different value as compared to QUN

$\mathrm{b}$ indicates significantly different value as compared to QUN/ $\beta C D$ (FDC)

c indicates significantly different value as compared to QUN/ $\beta C D / P O L O$ (FDC)

$\mathrm{d}$ indicates significantly different value as compared to QUN/HP $\beta C D / P O L O$ (FDC)

The QUN- $\beta C D$ and QUN-HP $\beta C D$ binary complexes increased the solubility of QUN by 3.4 and 9.6 folds respectively. On the other hand, QUN- $\beta C D-P O L O$ and QUN-HP $\beta C D-P O L O$ ternary complexes increase the solubility of QUN by 10.7 and 34.1 folds respectively. The physical mixtures showed slight enhancement in the solubility of QUN; however it was significantly less $(p<0.05)$ as compared to the complexes containing similar components. The dramatic improvement in the solubility of QUN in case of QUN-HP $\beta C D-P O L O$ ternary complexes can be ascribed to the formation of stable inclusion complex, and reduction in the crystallinity of drug. Besides, micellization of poloxamer chains may also contribute to some extent in enhancing the solubility of QUN. 


\subsection{Anti-inflammatory activity}

The results for anti-inflammatory activity with respect to change in paw volume and \% inhibition of paw inflammation (Mean \pm Std. Error) by using Carrageenan-induced rat paw edema method are shown in Figure 7. The positive control i.e. indomethacin decreased the paw volume by $28.07 \%$ after two hours. The percent inhibition of paw volume in case of QUN-HP $\beta$ CD-POLO ternary complex is $44.60 \%$ which is more as compared to pure QUN (27.55\%), indicating increased anti-inflammatory activity. The increased antiinflammatory activity confirmed the increase in bioavailability of QUN due to formation of stable inclusion complex between QUN and CDs in presence of POLO and improvement in its solubility.

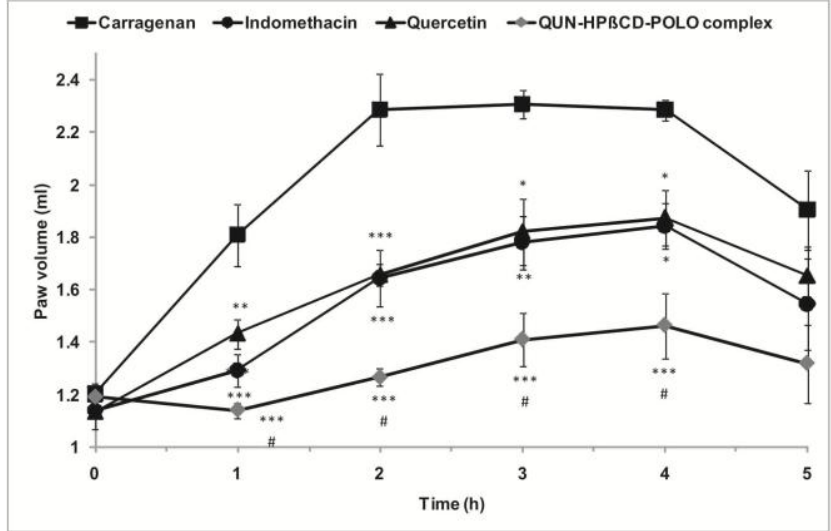

A

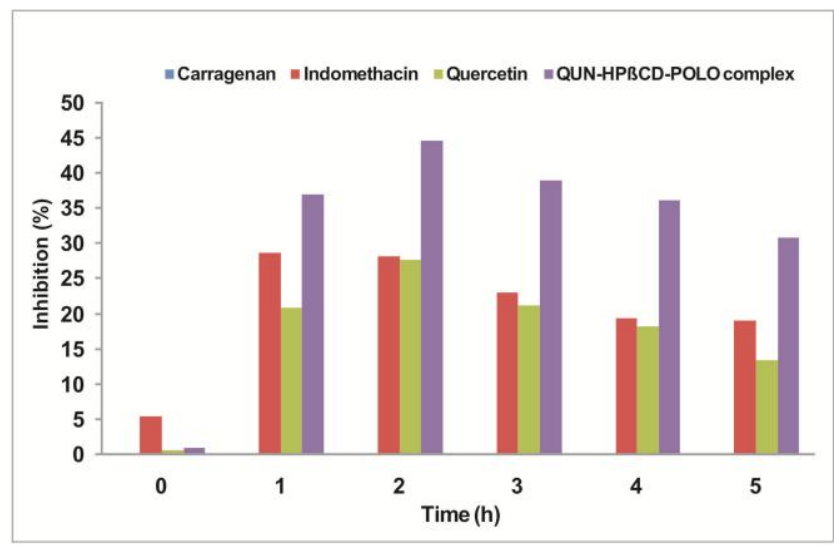

B

Figure 7. Anti-inflammatory activities of QUN and QUN-HP $\beta C D-P O L O$ ternary complex by Carrageenaninduced rat paw edema method: A- Effect on paw volume (ml); B- Inhibition of inflammation (\%). * indicates significant difference of paw volume with respect to control $\left({ }^{*}-\mathrm{p}<0.05\right.$; $\left.{ }^{* *}-\mathrm{p}<0.01 ;{ }^{* * *}-\mathrm{p}<0.001\right)$ and \# indicates significant difference of paw volume with respect to QUN treated group (\#- $\mathrm{p}<0.05)$.

\section{CONCLUSION}

The stability and complexation efficiency of $\beta C D$ and HP $\beta C D$ was markedly improved by POLO than the other hydrophilic polymers. QUN- $\beta C D-P O L O$ and QUN-HP $\beta C D-P O L O$ ternary complexes were successfully prepared using the lyophilization method. DSC and ATR-FTIR analysis helped to confirm the formation of inclusion complex whereas XRPD and SEM analysis revealed amorphous nature of the complexes. QUN-HP $\beta C D-P O L O$ complex showed high solubility than the other binary and ternary complexes. An increase in the in vivo anti-inflammatory activity of the QUN-HP $\beta C D-P O L O$ ternary complex clearly indicates enhancement in the bioavailability of QUN.

\section{MATERIALS AND METHODS}

\subsection{Materials}

QUN, $\beta C D$ and polyvinylpyrrolidone K30 (PVP) were purchased from Himedia Laboratories Pvt. Ltd., Mumbai, India. HP $\beta C D$ (DS: 4.69) was obtained as a gift sample from Gangwal Chemicals, Mumbai, India. Hydroxypropylmethylcellulose E15LV (HPMC) was purchased from Loba Chemie, Mumbai, India and Poloxamer 188 (POLO) was obtained from Signet Chemicals, Mumbai, India. The analytical grade reagents and glass distilled water were used (for the experimental procedures) throughout the experimental procedures.

\subsection{Phase solubility studies}

The phase solubility studies were performed in distilled water at room temperature $\left(25 \pm 2^{\circ} \mathrm{C}\right)$ according to the method reported by Higuchi and Connors [16]. The excess quantity of QUN was added to $20 \mathrm{~mL}$ of $\beta C D$ and $\mathrm{HP} \beta C \mathrm{C}$ solutions $(0$ to $0.01 \mathrm{M})$ in the presence and absence of auxiliary substances $(0.5 \% \mathrm{w} / \mathrm{v}$ of HPMC, PVP and POLO). The concentration of polymers was decided on the basis of the preliminary studies. The solubility of QUN in presence of fixed amount of CDs $(10 \mathrm{mM})$ and increasing polymer concentration $(0.25$, $0.5,0.75,1,1.5$ and $2 \% \mathrm{w} / \mathrm{v}$ ) was determined. The polymer concentration at which maximum QUN was solubilized was selected (i.e. $0.5 \% \mathrm{w} / \mathrm{v}$ ). The resultant suspensions were shaken for $72 \mathrm{~h}$ at $150 \mathrm{rpm}$ using 
rotary shaker (Lab HOSP, India) to attain equilibrium. Thereafter, suspensions were filtered using Whatman filter paper No. 41, appropriately diluted if necessary and analyzed to determine concentration of QUN using UV-spectrophotometer (Shimadzu 1800, Japan) at $371 \mathrm{~nm}$. The stoichiometry between QUN and CDs was established from the phase solubility curves obtained by plotting the concentration of dissolved QUN (moles/liter) against the respective concentration of CDs (moles/liter). The stability constants $\left(\mathrm{K}_{\mathrm{s}}\right)$ of the binary and ternary complexes were calculated using the equation [30].

$K_{s}=\frac{\text { Slope }}{S_{0}(1-\text { Slope })}$

Where, $\mathrm{S}_{0}$ is the solubility of QUN in distilled water.

The complexation efficiency (C.E.) of CDs was determined by the following equation [30].

C.E. $=K_{S} S_{0}=\frac{\text { Slope }}{(1-\text { Slope })}$

Gibbs free energy change $\left(\Delta G_{t r}\right)$ in Joules/mole was also calculated to assess the thermodynamics of the solution and complexation process, using the equation

$\Delta G_{t r}=-2.303 R T \log \frac{S_{c}}{S_{0}}$

Where, $S_{c}$ is molar solubility of QUN in aqueous solution of HP $\beta C D$ or $\beta C D$ in the presence or absence of hydrophilic polymer, $\mathrm{S}_{0}$ is molar solubility of QUN in distilled water, $\mathrm{R}$ is gas constant and $\mathrm{T}$ is temperature in Kelvin.

\subsection{Preparation of freeze dried solid inclusion complexes}

The method reported by Tayade et al [5] was used for preparation of binary and ternary complexes. The equimolar weighed quantities of QUN and CDs, were dissolved in distilled water $(70 \mathrm{~mL})$. To this aqueous solution, $25 \%$ ammonia $(1.5 \mathrm{~mL})$ was added to dissolve QUN. The resultant solutions were stirred using a magnetic stirrer $\left(2 \mathrm{MLH}\right.$, Remi laboratory Instruments, Mumbai), for $2 \mathrm{~h}$ at a room temperature $\left(25 \pm 2^{\circ} \mathrm{C}\right)$ and were frozen in deep freezer (ELCOLD) at $-80^{\circ} \mathrm{C}$ for 24 hours. The frozen solutions were lyophilized (DELVACmimiLyodel) and stored in desiccators till further use.

In case of ternary complexes, same procedure was followed by addition of POLO $(0.5 \% \mathrm{w} / \mathrm{w})$ in the complexation media. The physical mixtures of binary and ternary systems of QUN, CDs and POLO were prepared in order to compare their solubility with the complexes.

\subsection{Characterization of complexes}

\subsubsection{Differential scanning calorimetry (DSC)}

DSC analyzer (TA instuments Q600 SDT USA) was used to perform DSC analysis of QUN, $\beta C D$, $\mathrm{HP} \beta C D$, POLO and all complexes. A sample $(5 \mathrm{mg})$ was sealed in an aluminum pan and subjected to heating at a rate of $10^{\circ} \mathrm{C} / \mathrm{min}$ from $30-400{ }^{\circ} \mathrm{C}$ under nitrogen atmosphere.

\subsubsection{Attenuated Total Reflectance-Fourier Transform Infrared Spectroscopy(ATR-FTIR)}

Attenuated total reflectance (ATR)-Fourier transform infrared spectroscopy (FTIR) (BRUKER-ECOATR-ALPHA, Germany) was used for recording infrared spectra of QUN, $\beta C D, H P \beta C D$, POLO and prepared complexes. ATR-FTIR helps in direct analysis of the solid or liquid samples and does not require any complex sample preparation procedure. The samples were directly placed on ATR crystal and analyzed from 600 to $4000 \mathrm{~cm}^{-1}$ spectral range with 24 scans.

\subsubsection{X-ray powder diffractometry (XRPD)}

The XRPD analysis of all samples were performed by using X-ray diffractometer (PW 1723, PHILIPS, Netherland) with tube anode $\mathrm{Cu}$ over the interval 05-60。(20). Generator tension (voltage) $40 \mathrm{kV}$, Generator current $30 \mathrm{~mA}$, and scanning speed $2 \% / \mathrm{min}$. were maintained during the operation.

\subsubsection{Scanning electron microscopy (SEM)}


Scanning electron microscope (SEM-JOEL Instruments, JSM-6360A, Japan) was used for studying surface morphology of QUN and all complexes. Samples were directly mounted on the aluminum stub and coated with a thin gold-ion layer using sputter coated unit an acceleration voltage of $5 \mathrm{kV}$ was applied and the micrographs were examined at $\times 300, \times 1000$ and $\times 3000$ magnifications.

\subsection{Determination of drug content}

The content of QUN in the physical mixtures and complexes was determined by adding the physical mixtures/complexes equivalent to $5 \mathrm{mg}$ of QUN in $50 \mathrm{ml}$ of methanol. The resultant mixtures were stirred on the magnetic stirrer for $3 \mathrm{~h}$. The solutions were filtered through Whatman filter paper No. 41, suitably diluted and analyzed spectrophotometrtically at $371 \mathrm{~nm}$.

\subsection{Saturation solubility studies}

The saturation solubility of the pure QUN, physical mixtures and the complexes was determined using the method described by Higuchi and Connors [16]. Excess quantity of pure QUN and, prepared physical mixtures and complexes were added to the conical flasks each containing $10 \mathrm{ml}$ of distilled water and sealed. The mixtures were shaken using rotary flask shaker for $72 \mathrm{~h}$ at room temperature to attain equilibrium. Appropriate fractions were withdrawn and filtered through Whatman filter paper No. 41 and analyzed spectrophotometrically at $371 \mathrm{~nm}$.

\subsection{Anti-inflammatory activity}

The anti-inflammatory activity of optimized complex of QUN was evaluated in vivo as per the approval from Institutional Animal Ethics Committee (IAEC) of College of Pharmacy, Bhor, Maharashtra, India (Approval No. RDCOP/IAEC/Approval/2016-17/03 dated 08/08/2016). Carrageenan-induced rat paw edema method was used as reported previously [31,32].

\subsubsection{Experimental design}

The Wistar albino rats, 150-180 g of either sex were randomly divided into four groups of six rats in each.

\section{Group}

I . Control

II. Reference Standard: Indomethacin

III. Pure drug: QUN

IV. Test sample: QUN-HP $\beta C D-P O L O$
Dose

Treated with Normal saline

$10 \mathrm{mg} / \mathrm{kg}$ of body weight

$10 \mathrm{mg} / \mathrm{kg}$ of body weight

Equivalent to $10 \mathrm{mg}$ of QUN/ $\mathrm{kg}$ of body weight

To produce acute inflammation, $0.1 \mathrm{ml}$ of $1 \%$ freshly prepared carrageenan solution in normal saline was injected in right hind paw of rats by sub-plantar route. Control group rats were treated with normal saline, reference standard group with indomethacin $(10 \mathrm{mg} / \mathrm{Kg}$ body weight per oral), third group with pure QUN $10 \mathrm{mg} / \mathrm{Kg}$ body weight per oral and the test group with QUN-HP $\beta C D-P O L O$ ternary complex; quantity equivalent to $10 \mathrm{mg}$ of QUN/Kg body weight per oral respectively one hour prior to carrageenan injection. The paw volume was measured using plethysmometer at an interval of 1, 2, 3, 4 and 5 hrs after carrageenan injection and increase in mean paw volume in ml (Mean \pm Standard Error) and \% inhibition of paw inflammation was calculated.

The percentage inhibition of paw inflammation was calculated using the formula:

$\%$ inhibition of inflammation $=\frac{(\text { Control } \text { mean }- \text { Treated } \text { mean })}{\text { Control } \text { mean }} \times 100$

\subsection{Statistical analysis}

All values were shown as Mean \pm Standard Error Mean (S.E.M.). Statistical analysis was performed using one-way analysis of variance (ANOVA). $\mathrm{P}<0.05$ was considered statistically significant. 
Acknowledgements: The authors are thankful to Shivaji University, Kolhapur and Savitribai Phule Pune University, Pune for providing analytical facilities to perform characterization studies. The authors are thankful to the Principal, Government College of Pharmacy, Karad for providing necessary laboratory facilities and to the Principal, Rajgad Dnyanpeeth's College of Pharmacy, Bhor, Dist. Pune for providing necessary facilities for animal studies. The authors gratefully acknowledge Gangwal Chemicals, Mumbai for providing gift sample of HP $\beta C D$.

Author contributions: Concept - A.K., R.D.; Design - A.K., R.D.,; Supervision - R.D.; Materials - A.K; Data Collection and/or Processing - A.K., R.D.; Analysis and/or Interpretation - A.K., R.D., V.G.; Literature Search - A.K., R.D., V.G.; Writing - A.K.; Critical Reviews - R.D., V.G., A.K.

Conflict of interest statement: The authors declared no conflict of interest.

\section{REFERENCES}

[1] Borghetti GS, Lula IS, Sinisterra RD, Bassani VL. Quercetin/ $\beta$-cyclodextrin solid complexes prepared in aqueous solution followed by spray-drying or by physical mixture. AAPS PharmSciTech. 2009;10(1):235-242. [CrossRef]

[2] Zheng Y, Haworth IS, Zuo Z, Chow MSS, Chow AHL. Physicochemical and structural characterization of quercetinbeta- cyclodextrin complexes. J Pharm Sci. 2005;94(5):1079-1089. [CrossRef]

[3] Jullian C, Moyano L, Yañez C, Olea-Azar C. Complexation of quercetin with three kinds of cyclodextrins: An antioxidant study. Spectrochim Acta - Part A Mol Biomol Spectrosc. 2007;67(1):230-234. [CrossRef]

[4] Anand David A, Arulmoli R, Parasuraman S. Overviews of biological importance of quercetin: A bioactive flavonoid. Pharmacogn Rev. 2016;10(20):84-89. [CrossRef]

[5] Pralhad T, Rajendrakumar K. Study of freeze-dried quercetin-cyclodextrin binary systems by DSC, FT-IR, X-ray diffraction and SEM analysis. J Pharm Biomed Anal. 2004;34(2):333-339. [CrossRef]

[6] Li H, Zhao X, Ma Y, Zhai G, Li L, Lou H. Enhancement of gastrointestinal absorption of quercetin by solid lipid nanoparticles. J Control Release. 2009;133(3):238-244. [CrossRef]

[7] Penalva R, González-Navarro CJ, Gamazo C, Esparza I, Irache JM. Zein nanoparticles for oral delivery of quercetin: Pharmacokinetic studies and preventive anti-inflammatory effects in a mouse model of endotoxemia. Nanomedicine. 2017;13(1):103-110. [CrossRef]

[8] Jadhav P, Petkar B, Pore Y, Kulkarni A, Burade K. Physicochemical and molecular modeling studies of cefixime-1arginine-cyclodextrin ternary inclusion compounds. Carbohydr Polym. 2013;98(2):1317-1325. [CrossRef]

[9] Loftsson T, Brewster ME. Pharmaceutical applications of cyclodextrins. 1. Drug solubilization and stabilization. J Pharm Sci. 1996;85(10):1017-1025. [CrossRef]

[10] Loftsson T, Masson M. Cyclodextrins in topical drug formulations: Theory and practice. Int J Pharm. 2001;225(12):15-30. [CrossRef]

[11] Jadhav P, Pore Y. Physicochemical, thermodynamic and analytical studies on binary and ternary inclusion complexes of bosentan with hydroxypropyl- $\beta$-cyclodextrin. Bull Fac Pharm Cairo Univ. 2016;55(1):147-154. [CrossRef]

[12] Redenti E, Szente L, Szejtli J. Drug/cyclodextrin/hydroxy acid multicomponent systems. Properties and pharmaceutical applications. J Pharm Sci. 2000;89(1):1-8. [CrossRef]

[13] Gajare P, Patil C, Kalyane N, Pore Y. Effect of hydrophilic polymers on pioglitazone complexation with hydroxypropyl- $\beta$-cyclodextrin. Dig J Nanomater Biostruct. 2009;4(4):891-897.

[14] Pokharkar V, Khanna A, Venkatpurwar V, Dhar S, Mandpe L. Ternary complexation of carvedilol, beta-cyclodextrin and citric acid for mouth-dissolving tablet formulation. Acta Pharm. 2009;59(2):121-132. [CrossRef]

[15] Davis M, Brewster M. Cyclodextrin-based pharmaceutics: past, present and future. Nat Rev Drug Discov. 2004;3:1023-1035. [CrossRef]

[16] Higuchi T, Connors K. Phase solubility techniques. Adv Anal Chem Instr. 1965;117-212.

[17] Shah M, Pore Y, Dhawale S, Burade K, Kuchekar B. Physicochemical characterization of spray dried ternary microcomplexes of cefuroxime axetil with hydroxypropyl- $\beta$-cyclodextrin. J Incl Phenom Macrocycl Chem. 2013;76:391401. [CrossRef]

[18] Valero M, Pérez-Revuelta BI, Rodríguez LJ. Effect of PVP K-25 on the formation of the naproxen: $\beta$-cyclodextrin complex. Int J Pharm. 2003;253(1-2):97-110. [CrossRef] 
[19] Katzhendler I, Azoury R, Friedman M. Crystalline properties of carbamazepine in sustained release hydrophilic matrix tablets based on hydroxypropyl methylcellulose. J Control Release. 1998;54(1):69-85. [CrossRef]

[20] Sinha V, Anitha R, Ghosh S, Nanda A, Kumria R. Complexation of celecoxib with $\beta$-cyclodextrin: Characterization of the interaction in solution and in solid state. J Pharm Sci. 2005;94:676-687. [CrossRef]

[21] Loftsson T, Frikdriksdóttir H, Sigurkdardóttir AM, Ueda H. The effect of water-soluble polymers on drugcyclodextrin complexation. Int J Pharm. 1994; 110(2):169-177. [CrossRef]

[22] Bodratti A, Alexandridis P. Formulation of poloxamers for drug delivery. J Funct Biomater. 2018;9(1):pii E11. [CrossRef]

[23] Koontz JL, Marcy JE, O'Keefe SF, Duncan SE. Cyclodextrin inciusion complex formation and solid-state characterization of the natural antioxidants a-tocopherol and quercetin. J Agric Food Chem. 2009;57(4):1162-1171. [CrossRef]

[24] Srivalli KMR, Mishra B. Improved aqueous solubility and antihypercholesterolemic activity of ezetimibe on formulating with hydroxypropyl- $\beta$-cyclodextrin and hydrophilic auxiliary substances. AAPS PharmSciTech. 2016;17(2):272-283. [CrossRef]

[25] Yadav VR, Suresh S, Devi K, Yadav S. Effect of cyclodextrin complexation of curcumin on its solubility and antiangiogenic and anti-inflammatory activity in rat colitis model. AAPS PharmSciTech. 2009;10(3):752-762. [CrossRef]

[26] El-Maradny H, Mortada S, Kamel O, Hikal A. Characterization of ternary complexes of meloxicam-HP $\beta C D$ and PVP or L-arginine prepared by the spray-drying technique. Acta Pharm. 2008;58(4):455-466. [CrossRef]

[27] Chourasiya A, Upadhayay A, Shukla RN. Isolation of quercetin from the leaves of Azardirachta indica and antidiabetic study from the crude extracts. J Pharm Biomed Sci. 2012;25(25):179-181.

[28] Zou A, Zhao X, Handge UA, Garamus VM, Willumeit-Römer R, Yin P. Folate receptor targeted bufalin/ $\beta$ cyclodextrin supramolecular inclusion complex for enhanced solubility and anti-tumor efficiency of bufalin. Mater Sci Eng C. 2017;78:609-618. [CrossRef]

[29] Bulani VD, Kothavade PS, Kundaikar HS, Gawali NB, Chowdhury AA, Degani MS, Juvekar AC. Inclusion complex of ellagic acid with $\beta$-cyclodextrin: Characterization and in vitro anti-inflammatory evaluation. J Mol Struct. 2016;1105:308-315. [CrossRef]

[30] Brewster M, Loftsson T. Cyclodextrins as pharmaceutical solubilizers. Adv Drug Deliv Rev. 2007;59:645-666. [CrossRef]

[31] Winter CA, Risley EA, Nuss GW. Carrageenin-induced edema in hind paw of the rat as an assay for antiinflammatory drugs. Exp Biol Med. 1962;111:544-547. [CrossRef]

[32] Kaidama WM, Gacche RN. Anti-inflammatory activity of quercetin in acute and chronic phases of inflammation in Guinea pigs. Am J Phytomed Clin Ther 2015;3(2):129-136. 